\title{
ANALISIS BUTIR SOAL ISMUBA (AL-ISLAM KEMUHAMMADIYAHAN DAN BAHASA ARAB) KELAS IV SD MUHAMMADIYAH 5 JAKARTA SELATAN
}

\author{
Lismawati. Ari Khairurrijal Fahmi. \\ Program Studi Pendidikan Agama Islam dan \\ Program Studi Pendidikan Bahasa Arab Fakultas Agama Islam Universitas \\ Muhammadiyah Prof Dr Hamka \\ email: 1isma9741@gmail.com, arikhairurrijal@uhamka.ac.id
}

\begin{abstract}
Learning ISMUBA (al-Islam, Kemuhammadiyahan and Arabic) is the hallmark of an Education Institution in all Muhammadiyah schools. An institution that holds realization of learning al-Islam, Kemuhammadiyahan and Arabic language is SD Muhammadiyah 5 South Jakarta is one of the Muhammadiyah elementary school located in Jalan Limau Kebayoran Baru South Jakarta. The type of this research is descriptive quantitative with qualitative descriptive interpretation. Place conducted research In SD Muhammadiyah 5 Jakarta Selatan While the time of research from September to Novermber 2017. Population research is all students In SD Muhammadiyah 5 South Jakarta class IV. Sample used in this research is saturated population that is all student of Class IV. The data collected includes primary data. Primary data obtained from the answer sheet of students of SD Muhammadiyah 5 Jakarta Selatan on the subjects of alIslam, Kemuhammadiyahan and Arabic. Analysis of items by using IRT (Item Response Theory) by using item software to see the level of difficulty problem, distinguishing power. The results obtained from the ITEMAN application will be interpreted in accordance with the provisions of different problem power and problem level.
\end{abstract}

Keywords: ISMUBA, Item Response Theory. Muhammadiyah 5 Elementary School

\begin{abstract}
ABSTRAK
Pembelajaran ISMUBA (al-Islam, Kemuhammadiyahan dan Bahasa Arab) merupakan ciri sebuah Lembaga Pendidikan di seluruh sekolah Muhammadiyah. Salah satu sekolah yang mengadakan realisasi pembelajaran al-Islam, Kemuhammadiyahan dan bahasa arab adalah SD Muhammadiyah 5 yang berada di Jalan Limau Kebayoran Baru Jakarta Selatan. Jenis penelitian ini adalah deskriptif kuantitatif dengan interpretasi deskriptif kualitatif. Tempat dilaksanakan penelitian di SD Muhammadiyah 5 Jakarta Selatan. Waktu penelitian dari bulan September sampai November 2017. Populasi penelitian adalah seluruh siswa di SD Muhammadiyah 5 Jakarta Selatan kelas IV. Sampel yang dipakai dalam penelitian ini adalah populasi jenuh yaitu seluruh siswa kelas IV. Data yang dikumpulkan meliputi data primer. Data primer diperoleh dari hasil lembar jawaban siswa SD Muhammadiyah 5 Jakarta Selatan pada Mata pelajaran Al-Islam,
\end{abstract}


Kemuhammadiyahan dan Bahasa Arab. Analisis butir soal dengan menggunakan IRT (Item Respon Teori) dengan menggunakan software ITEMAN untuk melihat tingkat kesukaran soal, daya pembeda. Hasil yang diperoleh dari aplikasi ITEMAN akan diinterpretasikan sesuai dengan ketentuan daya beda soal dan tingkat kesukaran soal.

Kata Kunci : Ismuba, SD Muhammadiyah 5, IRT 


\section{PENDAHULUAN}

Analisis Butir soal merupakan salah satu bentuk dari serangkaian proses evaluasi dalam kegiatan belajar mengajar. Dalam jurnal Pendidikan Akuntansi Indonesia, Vol. X, No.1, Tahun 2012 dengan Judul Analisis Butir Soal Tes Kendali Mutu Kelas XII SMA Mata Pelajaran Ekonomi Akuntansi di Kota Yogyakarta Tahun 2012 dengan seri soal A, B, C, D, E diperoleh hasil penelitian yang menunjukkan bahwa validitas butir soal yang valid sebesar $87,5 \%$ untuk seri A, $95 \%$ soal seri B, 75\% soal seri C, 82,5\% soal seri D dan 75\% soal seri E. Reabilitas soal memiliki koefisien reliabilitas yang tinggi yaitu soal seri B dengan nilai koefisien 0,843. Berdasarkan tingkat kesukaran soal masuk dalam kategori sedang dan daya beda pembeda soal nya baik dan berdasarkan keefektivan penggunaan distractor soal berkualitas sangat baik.

Berdasarkan hasil penelitian tersebut diperoleh informasi terkait dengan kualitas butir soal. Hasil analisis butir soal di atas menunjukkan tingkat kevaliditasan soal, reabilitas soal daya beda soal dan keefektifan pengunaan distractor dalam pilihan ganda. Evaluasi pembelajaran adalah sistem yang artinya suatu rangkaian kegiatan yang melibatkan berbagai unsur sebagai satu kesatuan. Masing-masing unsur mempunyai fungsi dan peran tersendiri dan perubahan dalam salah satu unsur akan berpengaruh pada unsur yang lainnya. Dalam dunia pendidikan, evaluasi merupakan suatu kegiatan yang tak terpisahkan dan sama pentingnya dengan proses pembelajaran.

Evaluasi ini sangat penting sekali untuk dilaksanakan oleh tenaga pendidik, karena dapat dijadikan sebagai kegiatan pengendalian, penjaminan, penetapan mutu dan alat untuk mengukur tingkat keberhasilan peserta didik sebagai out put serta sebagai bentuk pertanggungjawaban penyelenggaraan pendidikan. Adapun salah satu bentuk dari evaluasi di sekolah yaitu berupa tes, ulangan, atau ujian mata pelajaran yang diberikan kepada peserta didik.

Dalam melakukan evaluasi terhadap alat pengukur yang telah digunakan untuk mengukur keberhasilan belajar dari para peserta didiknya (muridnya, siswa, mahasiswa dan lain-lain). Alat pengukur dimaksud adalah tes hasil belajar, yang sebagai mana telah kita maklumi, batang tubuhnya terdiri dari kumpulan butir-butir soal. Dalam aplikasinya mempunyai fungsi dan peranan yang sangat penting dalam hal untuk mengetahui tujuan yang ingin dicapai.

Tes atau ulangan ini juga untuk membantu dalam penjaminan mutu pendidikan itu sendiri. Hal ini selaras dengan Peraturan Pemerintah nomor 19 tahun 2005 tentang Standar 
Nasional Pendidikan pasal 64 ayat 1 yang menjelaskan bahwa penilaian hasil belajar oleh pendidik dilakukan secara berkesinambungan untuk memantau proses, kemajuan dan perbaikan hasil dalam bentuk ulangan harian, ulangan tengah semester, ulangan akhir semester dan ulangan kenaikan kelas.

Dalam Jurnal pendidikan Akuntansi Indonesia Vol 13, No 1 (2015), didapat hasil penelitian yang menunjukkan bahwa soal ujian akhir semester genap mata pelajaran Ekonomi Akuntansi Kelas XI IPS SMA N 1 Kalasan Tahun Ajaran 2013/2014 merupakan soal yang belum berkualitas baik. (1) Validitas soal menunjukkan 26 butir soal atau 52\% dikatakan valid dan 24 butir soal atau 48\% dikatakan tidak valid sehingga soal termasuk soal yang berkualitas baik dari segi Validitas. (2) Reliabilitas soal sebesar 0,727 sehingga soal termasuk soal yang berkualitas baik karena koefisien Reliabilitas yang tinggi. (3) Daya Pembeda soal menunjukkan 33 butir soal atau 66\% memiliki daya pembeda jelek, 11 butir soal atau 22\% memiliki daya pembeda cukup, 3 butir soal atau 6\% memiliki daya pembeda baik, dan 3 butir soal atau $6 \%$ memiliki daya pembeda tidak baik sehingga soal termasuk soal yang belum berkualitas baik dari segi Daya Pembeda. (4) Tingkat Kesukaran soal menunjukkan 5 butir soal atau $10 \%$ tergolong sukar, 15 butir soal atau 30\% tergolong sedang, dan 30 butir soal atau $60 \%$ tergolong mudah sehingga soal termasuk soal yang belum berkualitas baik dari segi Tingkat Kesukaran. (5) Efektivitas Pengecoh soal menunjukkan 1 butir soal atau 2\% memiliki pengecoh sangat baik, 7 butir soal atau 14\%memiliki pengecoh baik, 15butir soal atau $30 \%$ memiliki pengecoh cukup, 14 butir soal atau $28 \%$ memiliki pengecoh kurang baik, dan13 butir soal atau $26 \%$ memiliki pengecoh tidak baik sehingga soal termasuk soal yang belum berkualitas baik dari segi Efektivitas Pengecoh.

Dari penelitian tersebut, diperoleh informasi terkait dengan analisis butir soal mata pelajaran ekonomi Akuntansi Kelas XI IPS SMA N 1 Kalasan Tahun Ajaran 2013/2014 diperoleh informasi terkait daya beda soal, tingkat kesukaran soal dan pengecoh dari pilihan jawaban. Berdasarkan penelitian tersebut maka Peneliti akan melakukan analisis butir soal ISMUBA di SD Muhammadiyah 5 Jakarta Selatan.

Tujuan peneliti melakukan penelitian ini untuk menganalisis dalam rangka mencari tahu bagaimana kualitas butir soal dilihat dari validitas soal, reabilitas soal daya beda soal dan keefektifan pengunaan distractor dalam pilihan ganda khususnya pada mata pelajaran ISMUBA (Al-islam, Kemuhammadiyahan dan Bahasa Arab). 


\section{METODOLOGI PENELITIAN}

Metode Penelitian ini dengan menggunakan Metode Kuantitatif. Penelitian ini adalah penelitian deskriptif kuantitatif dengan interpretasi deskriptif kualitatif. Kuantitatif yaitu menggambarkan hasil jawaban butir soal peserta didik dengan menggunakan software aplikasi ITEMAN.

\section{HASIL DAN PEMBAHASAN}

\section{MATA PELAJARAN KEMUHAMMADIYAHAN}

$\mathrm{N}$ of Items 20

$\mathrm{N}$ of Examinees 26

Mean 11.385

Variance 6.160

Std. Dev. 2.482

Skew -0.459

Kurtosis -0.201

Minimum 5.000

Maximum 16.000

Median 12.000

Alpha 0.393

SEM 1.934

Mean P 0.569

Mean Item-Tot. 0.283

Mean Biserial 0.390 jumlah soal adalah 20

jumlah peserta tes adalah 26 siswa

jumlah rata-rata peserta ujian 11.385 dari 20 soal

jumlah kuadrat dari standar deviasi

simpangan baku hasil ujian

distribusi data normal karena Skew -0.459 (normal -2 sampai 2)

distribusi data normal karena kurtosis-0.201(normal -2 sampai 2)

nilai minimum peserta 5

nilai maksimum peserta 16

nilai tengah dari statistik

reliabilitas soal $39.3 \%$ di bawah minimal $70 \%$

nilainya cukup besar, sebaiknya di bawah 1

rata-rata tingkat kesukaran soal 0.569 berkategori sedang karena di antara range $0.30-0.70$

daya pembeda baik, $\mathrm{D}=0.20-0.40$, jadi soal sudah cukup dan tidak perlu direvisi

Dari 20 soal di atas dapat disimpulkan bahwa hasil sebagai berikut :

A. Tingkat Kesukaran ( Prop. Correct ) :

1. Sukar ( p 0.00 sampai 0.30 ) : 4 soal ( $20 \%$ dari jumlah soal )

2. Sedang ( p 0.30 sampai 0.70 ) : 9 soal ( $45 \%$ dari jumlah soal )

3. Mudah ( $\mathrm{p} 0.70$ sampai 1 ) : 7 soal ( $35 \%$ dari jumlah soal)

B. Daya Pembeda :

1. Jelek $(\mathrm{D}=0.00-0.20) \quad: 1$ soal $(5 \%$ dari jumlah soal $)$

2. Cukup $(\mathrm{D}=0.20-0.40) \quad: 5 \operatorname{soal}(25 \%$ dari jumlah soal $)$

3. Baik $(\mathrm{D}=0.40-0.70) \quad: 12$ soal $(60 \%$ dari jumlah soal $)$

4. Baik Sekali $(\mathrm{D}=0.7-1) \quad$ : 0 soal $(0 \%$ dari jumlah soal $)$

5. Jelek Sekali ( Negatif) : 2 soal ( $10 \%$ dari jumlah soal )

\section{MATA PELAJARAN BAHASA ARAB}

$\mathrm{N}$ of Items 20

$\mathrm{N}$ of Examinees 27

Mean 13.074

Variance 46.365 jumlah soal adalah 20

jumlah peserta tes adalah 27 siswa jumlah rata-rata peserta ujian 13.074 dari 20 soal jumlah kuadrat dari standar deviasi 
Std. Dev. 6.809

Skew -0.739

Kurtosis-1.030

Minimum 0.000

Maximum 20.00

Median 15.000

Alpha 0.958

SEM 1.392 simpangan baku hasil ujian

distribusi data normal karena Skew -0.739 (normal -2 sampai 2)

distribusi data normal karena kurtosis -1.030 (normal-2 sampai2)

nilai minimum peserta 0

nilai maksimum peserta 20

nilai tengah dari statistik

reliabilitas soal $95.8 \%$ di atas minimal $70 \%$

nilainya cukup besar, sebaiknya di bawah 1

rata-rata tingkat kesukaran soal 0.654 berkategori sedang Karena di antara range $0.30-0.70$

Mean Item-Tot. 0.750

Mean Biserial 0.918

daya pembeda baik, $\mathrm{D}=0.70-1$, jadi soal sudah baik sekali dan tidak perlu direvisi

Dari 20 soal di atas dapat disimpulkan bahwa hasil dari :

A. Tingkat Kesukaran ( Prop. Correct ) :

1. Sukar ( p 0.00 sampai 0.30 ) : 1 soal ( $5 \%$ dari jumlah soal )

2. Sedang ( p 0.30 sampai 0.70 ): 8 soal ( $40 \%$ dari jumlah soal )

3. Mudah ( p 0.70 sampai 1 ): 11 soal ( $55 \%$ dari jumlah soal )

B. Daya Pembeda :

1. Jelek ( $\mathrm{D}=0.00-0.20): 0$ soal ( $0 \%$ dari jumlah soal $)$

2. Cukup ( $\mathrm{D}=0.20-0.40): 0$ soal ( $0 \%$ dari jumlah soal $)$

3. Baik $(\mathrm{D}=0.40-0.70)=: 6$ soal $(30 \%$ dari jumlah soal $)$

4. Baik Sekali ( $\mathrm{D}=0.7-1): 14$ soal ( $70 \%$ dari jumlah soal )

5. Jelek Sekali ( Negatif) : 0 soal ( $0 \%$ dari jumlah soal )

\section{MATA PELAJARAN AL-ISLAM}

$\mathrm{N}$ of Items 20

$\mathrm{N}$ of Examinees 26

Mean 14.731

Variance 9.197

Std. Dev. 3.033

Skew -0.462

Kurtosis -0.586

Minimum 8.000

Maximum 20.000

Median 15.000

Alpha 0.682

SEM 1.711 jumlah soal adalah 20

jumlah peserta tes adalah 26 siswa

jumlah rata-rata peserta ujian 14.731 dari 20 soal

jumlah kuadrat dari standar deviasi

simpangan baku hasil ujian

distribusi data normal karena Skew -0.462 (normal -2 sampai 2)

distribusi data normal karena kurtosis -0.586(normal -2sampai 2)

nilai minimum peserta 8

nilai maksimum peserta 20

nilai tengah dari statistik

reliabilitas soal $68.2 \%$ di bawah minimal $70 \%$

nilainya cukup besar, sebaiknya di bawah 17

rata-rata tingkat kesukaran soal 0.737 berkategori mudah Karena di antara range $0.70-1$

Mean Item-Tot. 0.382 
Mean Biserial 0.545 daya pembeda baik, $\mathrm{D}=0.40-0.70$, jadi soal sudah cukup baik dan tidak perlu direvisi

Dari 20 soal di atas dapat disimpulkan bahwa hasil dari :

A. Tingkat Kesukaran ( Prop. Correct ) :

1. Sukar ( p 0.00 sampai 0.30 ) : 0 soal ( $0 \%$ dari jumlah soal)

2. Sedang ( p 0.30 sampai 0.70 ): 9 soal ( $45 \%$ dari jumlah soal )

3. Mudah ( p 0.70 sampai 1 ): 11 soal ( $55 \%$ dari jumlah soal )

B. Daya Pembeda :

1. Jelek ( $\mathrm{D}=0.00-0.20)$ : 1 soal ( $5 \%$ dari jumlah soal $)$

2. Cukup ( $\mathrm{D}=0.20-0.40$ ): 6 soal ( $30 \%$ dari jumlah soal )

3. Baik ( $\mathrm{D}=0.40-0.70)$ : 11 soal ( $55 \%$ dari jumlah soal )

4. Baik Sekali ( $\mathrm{D}=0.7-1)$ ): 0 soal ( $0 \%$ dari jumlah soal )

5. Jelek Sekali ( Negatif) : 2 soal ( $10 \%$ dari jumlah soal)

Soal yang perlu di revisi karena nilai Prop Endorsing 0 atau semua pengoceh pilihan nilainya 0 yaitu nomor soal 3 .

\section{SIMPULAN}

Berdasarkan hasil pembahasan dapat ditarik kesimpulan bahwa analisis butir soal adalah tahapan analisi yang sistematis untuk mendapatkan informasi karakteristik terhadap butir soal yang ingin dilihat. Karakteristik butir soal tersebut dapat dilihat berdasarkan Tingkat kesukaran, Daya pembeda, Fungsi Pengecoh.

Hasil dari analisi butir soal kemuhammadiyahan yaitu :

1. Reliabilitas set soal kemuhammadiyahan adalah 39.3\%.. Nilai ini dapat dikatakan kurang karena di bawah minimal $70 \%$.

2. Tingkat kesukaran terdapat 7 butir soal mudah, 9 butir sedang, dan 4 butir sukar.

3. Butir soal yang tidak memenuhi daya pembeda soal ada soal 3 butir soal yaitu butir soal nomor 9,14 dan 20

4. Butir soal yang tidak memenuhi fungsi pengecoh ada 6 butir soal yaitu butir soal nomor $7,11,13,14,18$ dan 20

5. Tidak ada Butir soal yang harus dibuang dari set soal kemuhammadiyahan 
Hasil dari analisi butir soal Bahasa Arab yaitu :

1. Reliabilitas set soal Bahasa Arab adalah 95.8\%.. Nilai ini dapat dikatakan cukup karena di atas minimal $70 \%$.

2. Tingkat kesukaran terdapat 11 butir soal mudah, 8 butir sedang, dan 1 butir sukar.

3. Tidak ada butir soal yang tidak memenuhi daya pembeda soal

4. Tidak ada butir soal yang tidak memenuhi fungsi pengecoh

5. Tidak ada Butir soal yang harus dibuang dari set soal Bahasa Arab

Hasil dari analisi butir soal AL-Islam yaitu :

1. Reliabilitas set soal kemuhammadiyahan adalah $68.2 \%$.. Nilai ini dapat dikatakan cukup karena di atas minimal $70 \%$.

2. Tingkat kesukaran terdapat 11 butir soal mudah, 9 butir sedang, dan 0 butir sukar.

3. Butir soal yang tidak memenuhi daya pembeda soal ada soal 3 butir soal yaitu butir soal nomor 3,15 dan 18

4. Butir soal yang tidak memenuhi fungsi pengecoh ada 1 butir soal yaitu butir soal nomor 18

5. Butir soal yang harus dibuang dari set soal Al Islam yaitu soal nomor 3 


\section{DAFTAR PUSTAKA}

Amalia, Ata Nayla \& Ani Widayati. Analisis Butir Soal Tes Kendali Mutu Kelas XII SMA Mata Pelajaran Ekonomi Akuntansi di Kota Yogyakarta Tahun 2012 . Jurnal Pendidikan Akuntansi Indonesia, Vol. X, No.1, Tahun 2012

Arikunto, Suharsimi (2015), Dasar-dasar Evaluasi Pendidikan, Jakarta: Bumi Aksara.

Cronbach,L.J (1971), Test Validation, Dalam R.L. Thorndike (Ed) Educatioanal Measurement. (2nd ed) Washington DC: American Council on Education. Fernandes, H.J.X (1984), Testing and Measurement, Jakarta: Nasional Education Planing Evaluation and Curriculum Development.

Depdikbud, 1999, Pengelolaan Pengujian Bagi Guru Mata Pelajaran, Jakarta.

Djemari Mardapi, 2004, Penyusunan Tes Hasil Belajar. Yogyakarta: UNY

Hambleton, Ronald K.H Swaminathan and H. Jane Rogers (1991), Fundamentals of Item Response Theory, New Bury Park, London, New Delhi: Sage Publications.

Ign. Masidjo. 1995, Penilaian Hasil Belajar Siswa di Sekolah. Yogyakarta: Kanisius. Linn R L (1989), Educational Measurement, New York: Mac Millan Publishing.

Majid, Abdul. 2008. Perencanaan Pembelajaran. Bandung: Rosda

Mardapi, Djemari, (1998), "Analisis Butir dengan Teori Klasik dan teori Respon Butir" dalam Jurnal kependidikan, edisi khusus Dies, tahun XXVIII, Yogyakarta: IKIP Yogyakarta.

Mehren, W.A \& Lehmann, I.J (1984), Measurement and Evaluation in Educational and Psychology, New York: Holt, Rinehart, Winston.

Naga, Dali,S (1992), Pengantar Teori Sekor, Jakarta: PT Gunadarma.

Nana Sudjana, 2005, Penilaian Hasil Proses Belajar Mengajar. Bandung: Remaja Rosdakarya

Ngalim Purwanto, 2004, Prinsip-prinsip dan Teknik Evaluasi Pengajaran. Bandung: Remaja Rosdakarya.

Suharsimi Arikunto, 2006, Dasar-dasar Evaluasi Pendidikan. Jakarta: Bumi Aksara

Sukardjo, 2008, Modul Perkuliahan Evaluasi Pembelajaran Sains Pascasarjana UNY. Yogyakarta

Suryabrata, Sumadi (1997), Pengembangan Tes Hasil Belajar, Jakarta: Rajawali. 